DURING COVID-19

Maintaining Career Momentum: Women-Centered Strategies for Social Sciences Career Success in the Context of COVID-19

Courtney Cronley and Kristen E. Ravi

University of Tennessee 


\begin{abstract}
The COVID-19 pandemic poses unforeseen risks to women's academic career advancement. Women faculty are more likely to be grappling with new challenges related to caregiving and work-life balance, compared to their male colleagues, and may be facing more research obstacles due to the disruption of human-subjects data collection. In the following essay, we, two tenurestream social scientists, describe four strategies that we have relied on to maintain career momentum: staying passionate, engaging in active mentorship, making virtual connections, and launching research in COVID. We conclude with recommendations for institutions of higher education to formalize specific policies to support gender and intersectional equity in career advancement. These include more formalized mentor programs, professional development for and access to technology resources for the purposes of research, institutional training and support in leading research teams, seed grants for racial and gender disparities research, and pro-family policies that provide financial supports and job security in the context of caregiving.

Keywords: social science, human-subjects data collection, mentorship, technology, social justice
\end{abstract}


DURING COVID-19

\section{Maintaining Career Momentum: Women-Centered Strategies for Social Sciences Career Success in the Context of COVID-19}

COVID-19 has disrupted family routines, causing school and childcare closures, placing older adults in positions of greater vulnerability, and putting ever more caregiving demands on women adults in the household. Among women academics, COVID has exacerbated pre-existing work-life balance stressors (Guy \& Arthur, 2020; Khan et al., 2019; Minello, 2020) and gender disparities in career advancement (Gruber et al., 2020; Lopez et al., 2018; Schisterman et al., 2017), leading to notable declines in women's publication outputs (Andersen et al., 2020; Flaherty, 2020). Academics who are women and Black, Indigenous, and Persons of Color (BIPOC), as well as single-parents or sexual/gender minorities, face intersectional challenges related to racism, institutional bias, and economic constraints, such that COVID presents unique and disproportionate impediments to academic career advancement (Fulweiler et al., 2021), in addition to potential for experiencing greater personal loss (Gross et al., 2020) and collective trauma compared to their white colleagues.

Recent empirical work has explored the intensified tensions that COVID has created for academic mothers (Guy \& Arthur, 2020). In the following essay, we build on that work and identify four strategies that we, two mothers and academic social scientists, developed for maintaining career momentum. Our strategies are predicated on our methodological training with human subjects, and commitment to studying social issues that disproportionately place women in highly vulnerable situations, specifically homelessness and intimate partner violence. In this essay, we intentionally focus on critical feminist and intersectional research involving humansubjects; women scientists may be more likely to work in fields involving human-subjects' datacollection (West et al., 2013). COVID-19 and social distancing uniquely disrupted these 
methodologies, creating additional structural barriers to women scholars' research and careers during and post-pandemic. We acknowledge, however, that our experiences are advantaged by our positions as white, cisgender, and married. For women occupying intersectional spaces, e.g., BIPOC, sexual minority, or single parenting, the stakes are higher and the potential to access career critical resources more difficult.

\section{Our COVID Survival Strategies}

\section{Strategy 1: Staying Passionate}

For both of us, the pandemic initially led to panic, exhaustion, and frustration as we struggled to juggle working remotely with pre-school-age children home all day with us. It was difficult to concentrate on research and writing and easier to focus on the tangible aspects of teaching. One strategy that we used to overcome the research anomie was by reminding ourselves about the contemporary importance of our research. The pandemic revealed and exacerbated the intersectional race-, gender- and income-based disparities that we already know from our research; anecdotal accounts from front-line workers with our community providers described women's struggles, such as accessing remote learning for their children in emergency shelters, experiencing trauma flashbacks, and economic setbacks. We saw the importance of documenting these struggles in empirical research. Thus, as we moved through the pandemic, we found renewed energy and passion to produce critical scholarship that advances the rights and opportunities of women, particularly those facing disadvantage due to intersectional positions such as lower income or minority race.

\section{Strategy 2: Engaging in Active Mentorship}

The second strategy, active mentorship, served as the center point for our subsequent strategies. $\mathrm{CC}$ as a tenured associate professor, serves as the mentor, while $\mathrm{KR}$ is tenure-earning 
and occupies the mentee role. Formal mentorship programs, supported by academic leadership, benefits women academics in terms of productivity, job satisfaction, and professional development (Cross et al., 2019; Gaughan et al., 2017; Morrow, 2019). However, we received no formal instructions or orientation to the mentorship process other than being pointed to the written policy in the college's policies and procedures. Lacking formal processes, we built a model of reciprocal mentorship (Jones \& Brown, 2011), and utilized a reframing approach (McDougall \& Connolly, 2020). During regular monthly meetings, we strategized about KR's 5year plan. Using reframing, we adapted our research plans to COVID challenges and discussed new ways for KR to build out her pre-tenure professional networks. In the collaborative strategy, we applied and were awarded university funding to support a seed research study. The active nature of the mentorship - regular meetings, reframing challenges, and identifying collaborative projects - makes us both accountable to the mentorship relationship. The model we propose here may be particularly beneficial for women academics in intersectional positions. Senior BIPOC women academics are disproportionately asked to take on mentorship and support roles leading to invisible and burdensome service loads (Social Sciences Feminist Network Research Interest Group, 2017). An active mentorship model that confers mutual benefits could offset service and help mentors achieve career milestones while supporting their mentees.

\section{Strategy 3: Making Virtual Connections}

Professional networks, in the form of other academics, are linked to career success (Gaughan et al., 2017), and they be particularly important for BIPOC women academics (Settles, 2019). However, COVID-19 initially slowed down networking opportunities as universities adjusted to new virtual realities. The shift to remote engagement created different opportunities, though. We re/connected with faculty members within our college and across the university and 
DURING COVID-19

other institutions through virtual meet-and-greets and happy hours. Virtual events lower barriers to attendance, particularly for faculty with children at home (Remmel, 2021; Viglione, 2020) and may create more equitable spaces where BIPOC and women faculty feel more at ease to participate fully (Ferguson, 2020). We also connected with other academic mothers through social media groups, which offers both academic-related and motherhood-related support (Pontes et al., 2019).

In addition to building our academic networks, we refined the ways that we foster community partnerships. Institutions of higher education value community-engaged scholarship (Boyer, 1990; Holland, 2005), but doing this scholarship requires strong community-academic partnerships. During COVID-19, KR participated in a university-sponsored online community engagement academy for faculty that disseminated the principles and best practices of building community partnerships. Moreover, while building these partnerships virtually has been challenging without the feeling of synergy in the room typically generated in an in-person meeting, Zoom seems to have increased the likelihood of community partners' accepting and attending meetings, perhaps because it lowers logistical barriers to attendance (Cronley et al., 2021).

\section{Strategy 4: Launching Research During COVID-19}

At the start of the pandemic, a university-suspension of in-person research presented itself as an opportunity to pause and re-assess our research agenda. The time to find funding and build teams is critical given the increasing expectations that academic scientists, across disciplines, participate in externally-funded, multi-disciplinary team science (Hall et al., 2018; Zerhouni, 2003). Pre-COVID, though, we often found that our packed schedules precluded time for quiet reflection and brainstorming. Early in COVID, we had time to search for grant 
DURING COVID-19

opportunities, and utilized a snowball method to build our team through virtual introductions.

Ever mindful of Zoom fatigue (Wiederhold, 2020), we built the team through multiple

modalities, including offline communications and cloud spaces like Onedrive, preferring to meet synchronously only when necessary.

In conducting research, we faced new barriers to engaging participants from populations that are lower-income and have inconsistent access to Broadband and digital technologies. Building on Strategy 3, we relied on community relationships to help us recruit participants, who were engaged in services with local agencies. We reframed methodological challenges as opportunities for innovation and designed research protocol to protect human subjects within the context of social distancing. When conducting focus groups online, we emailed informed consent documents to participants ahead of time and sent Zoom meetings links only after receiving the electronic signatures in order to limit attendance to those with documented consent. In another protocol, we proposed to utilize the white board function of Zoom to allow focus group participants to draw their responses. While the methods that we utilized to engage research participants may be more specific to social scientists, the issue of flexible methodologies and resilient research agendas is applicable across the sciences, including those working with restricted data and bench scientists who were unable to physically access data and labs during COVID.

\section{Conclusion}

COVID presented unique impediments to career momentum for women academics engaged in human subjects' research, and in conjunction with the racial pandemic, BIPOC women academics have encountered intersectional challenges. The strategies we highlighted above offer practical actions that women faculty, across a variety of intersectional identities, can 
take to survive and thrive. It is important to note, though, that we benefited from racial and sexual orientation positions of privilege, as well as from the assistance of our families who stepped in at critical times with childcare and logistical support. Women faculty in intersectional positions of marginalization face exponential at times existential hurdles. Universities cannot expect women faculty to succeed by relying on their personal resources, because doing so only exacerbates disparities based on level of social support, economic resources, race, and/or sexual and gender orientation.

In this light, we conclude by calling on institutions of higher education to institutionalize supports for women faculty, across all intersectional positions. Move beyond simply encouraging mentorship or matching pairs, and create structured mentorship expectations and training for mentors (National Academies of Sciences, Engineering, and Medicine, 2019). Support faculty development of community-engaged scholarship with vulnerable populations, and recognize this work in tenure and promotion guidelines. In addition, offer professional development for academic scientists on building resilient research agendas through training in multiple methods, including in-person and virtual data collection strategies. Furthermore, consider technical supports. Many institutions still require faculty to purchase resources like Zoom accounts and cameras with discretionary funds, and making these resources standard could improve work equity and productivity. In addition, universities can facilitate critical and intersectional team science by creating internal seed grants for racial and gender equity research teams. Moreover, universities can recognize research teams that reflect gender and racial diversity, and provide professional development opportunities for women and BIPOC faculty to develop research leadership skills necessary to lead research teams. Others have recommended eliminating the expiration date on start-up funds (Fulweiler et al., 2021), knowing that academic mothers and 
DURING COVID-19

BIPOC women faculty may progress at a differential pacing compared to traditional white male academic pathways.

Finally, and we believe, most importantly, institutions of higher education must take more progressive positions on family caregiving policies. Such positions would include offering: 1) paid family leave for caregiving needs across the lifespan, 2) onsite childcare, 3) tenure extensions, and 4) sincerity in application, meaning that family leave and clock extensions are not granted with implicit expectations to show comparable productivity during the clock extension or to make up the time with extra productivity in other years (Fulweiler et al., 2021; McCucheon \& Morrison, 2016). COVID-19 presents both challenges and opportunities for gender and intersectional inequities in higher education. In revealing the extent of disparities in career opportunities and progression, the pandemic makes it starkly clear that the time for higher education to dismantle these structural gender and race disparities is now. 


\section{References}

Alon, T., Doepke, M., Olmstead-Rumsey, J., \& Tertile, M. (2020, April). The impact of COVID19 on gender equality. NBER Working Paper No. 26947. JEL No. D10,E24,J16,J22.

Andersen, J. P., Nielsen, M. W., Simone, N. L., Lewiss, R. E., \& Reshma, J. (2020). COVID-19 medical papers have fewer women first authors than expected. Elife

Boyer, E. L. (1990). Scholarship reconsidered: Priorities of the professoriate. Princeton, NJ: The Carnegie Foundation for the Advancement of Teaching.

Cronley, C., Miller, V. J., Fields, N., \& Mattingly, S. (2021). Utilizing an interprofessional community advisory board: A case study to inform best practices in community-engaged research for transportation equity and social inclusion. Transportation Research Interdisciplinary Perspectives. DOI: https://doi.org/10.1016/j.trip.2021.100365

Fishman, M., Williams, W. A., Goodman, D. M., \& Ross, L. F. (2017). Gender differences in authorship of original research in pediatric journals, 2001-2016. Journal of Pediatrics, 1919, 244-249. doi: 10.1016/j.jpeds.2017.08.044.

Ferguson, K. (2020, July 21). Ten reasons why virtual meetings are the best thing to happen in 2020. Forbes. https://www.forbes.com/sites/kirstinferguson/2020/07/21/ten-reasons-whyvirtual-meetings-are-the-best-thing-to-happen-in-2020/?sh=4fb2d4457cd0

Flaherty, C. (2020, April 21). No room of one's own. Inside Higher Ed. https://www.insidehighered.com/news/2020/04/21/early-journal-submission-datasuggest-covid-19-tanking-womens-research-productivity

Fulweiler, R., Davies, S., Biddle, J., Burgin, A., Cooperdock, E., Hanley, T., Kenkel, C., Marcarelli, A., Matassa, C., Mayo, T., Santiago-Vàzquez, L., Traylor-Knowles, N., \& Ziegler, M. (2021). Rebuild the Academy: Supporting academic mothers during COVID- 
DURING COVID-19

19 and beyond. PLoS Biology, 19(3), e3001100-e3001100.

https://doi.org/10.1371/journal.pbio.3001100

Garijo, B. (2020, April). COVID-19 highlights how caregiving fuels gender inequality. The World Action Forum COVID Action Platform. https://www.weforum.org/agenda/2020/04/covid-19-highlights-how-caregiving-fuelsgender-inequality/

Gross, C. P., Essien, U. R., Pasha, S. Gross, J. R., Wang, S., \& Nunez-Smith, M. (2020). Racial and ethnic disparities in population-level COVID-19 mortality. Journal of General Internal Medicine, 35, 3097-3099.

Guy, B. \& Arthur, B. (2020). Academic motherhood during COVID-19: Navigating our dual roles as educators and mothers. Gender, Work, and Organizations. DOI:

$10.1111 /$ gwao. 12493

Hall, K. L., Vogel, A. L., Huang, G. C., Serrano, K. J., Rice, E. L., Tsakraklides, S. P., \& Fiore, S. M. The science of team science: A review of the empirical evidence and research gaps on collaboration in science. American Psychologist, 73(4), 532-548.

Holland, B. (2005). Scholarship and mission in the $21^{\text {st }}$ century university: The role of engagement. Australian Universities Quality Agency Forum, 11-15.

Jones, R., \& Brown, D. (2011). The mentoring relationship as a complex adaptive system: Finding a model for our experience. Mentoring \& Tutoring: Partnership in Learning, 19(4), 401-418.

Khan, M., Lakha, F., Jin Tan, M. M., Singh, S. R., Quek, R. Y. C., Han, E., Tan, S. M., Haldane, V., Gae-Sánchez, M., \& Legido-Quigley, H. (2020). More talk than action: Gender and ethnic diversity in leading public health universities. Lancet, 393, 594-600. 
Lopez, C. M., Margherio, C., Abraham-Hilaire, L. M., \& Feghali-Bostwick, C. (2018). Gender disparities in faculty rank: Factors that affect advancement of women scientists at academic medical centers. Social Sciences, 7(62), 1-18. doi:10.3390/socsci7040062

McCutcheon, J., \& Morrison, M. (2016). “Eight Days a Week”: A National Snapshot of Academic Mothers’ Realities in Canadian Psychology Departments. Canadian Psychology = Psychologie Canadienne, 57(2), 92-100. https://doi.org/10.1037/cap0000049

McDougall, R., \& Connolly, M. (2020). Mentoring as reframing: A useful conceptualization of dyadic multidisciplinary mentoring in academia. Advance, 22(1) 138-145.

Minello, A. (2020, April 17). The pandemic and the female academic. Nature, $\underline{\text { https://doi.org/10.1038/d41586-020-01135-9 }}$

Morrow, S. L. (2020). Identities, contradictions, and intersections: Feminist mentorship and leadership in academe. Women \& Therapy, 43(1-2), 197-212.

National Academies of Sciences, Engineering, and Medicine. 2019. The Science of Effective Mentorship in STEMM. Washington, DC: The National Academies Press. https://doi.org/10.17226/25568.

Pontes, T.B., Alves, A.T., Celeste, L.C., Bernardo, L.D., Queiroz, A.G., Poletto, M., \&

Njelesani, J. (2019). Academic mothers: balancing the roles of parent and researcher. Cadernos de Terapia Ocupacional Da UFSCar, 27(4), 687-690. https://doi.org/10.4322/2526-8910.ctoED2704

Remmel, A. (2021). Scientists want virtual meetings to stay after the COVID pandemic. Nature (London), 591(7849), 185-186. https://doi.org/10.1038/d41586-021-00513-1

Schisterman, E. F., Swanson, C. W., Lu, Y-L., \& Mumford, S. L. (2017). The changing face of 
epidemiology: Gender disparities in citations? Epidemiology, 28(2), 159-168.

https://dx.doi.org/10.1097/EDE.0000000000000593

Social Sciences Feminist Network Research Interest Group. (2017). The burden of invisible work in academia: Social inequalities and time use in five university departments. Humboldt Journal of Social Relations, 39(39), 228-245.

Viglione, G. (2020). How scientific conferences will survive the coronavirus shock. Nature (London), 582(7811), 166-167. https://doi.org/10.1038/d41586-020-01521-3

West, J. D., Jacquet, J., King, M. M., Correll, S. J., \& Bergstrom, C. T. (2013). The role of gender in scholarly authorship. PLOS ONE, 8(7), 1-6.

Zerhouni, E. (2003). The NIH Roadmap. Science, 302(5642), 63-72. 